\title{
GAYA KEPEMIMPINAN, MOTIVASI KERJA DAN DISIPLIN KERJA TERHADAP KINERJA KARYAWAN (PT BANK PEMBANGUNAN DAERAH (BPD) SUMATERA BARAT)
}

\author{
${ }^{1}$ Titik Efnita \\ ${ }^{1}$ Universitas Putera Batam \\ Tefnita12@gmail.com
}

\begin{abstract}
This Research Aims To Uncover The Influence Of Leadership Style, Work Motivation And Work Discipline Of Employee Performance. The population of this study are all employees At PT.Bank Regional Development (BPD) West Sumatra Branch Painan which amounted to 45 people. Samples were taken from all populations of 45 people. The analysis method uses multiple regression analysis. The results obtained: Multiple effect of variable X together to variable Y at PT.Bank Regional Development (BPD) West Sumatera Painan Branch is equal to 0,573 or 57,3\% with Sig. F at $0.000<0,05$ or Fthitung nilat bigger than $F$ table that is 26,445> 3,34, hence can be said that leadership style (X1) work motivation (X2) and work discipline (X3) have positive and significant influence to Performance employees of PT.Bank Regional Development (BPD) West Sumatera Painan Branch. Partially, leadership style have positive and significant influence to employees performance of PT.Bank Regional Development (BPD) West Sumatera Painan Branch where $t$ arithmetic variable of leadership style bigger than t table ( $t$ count 2,713> t table 1,9883) or its significance is smaller than alpha $(0,010<0,05)$. Partial of work motivation have positive and significant effect to employee performance of PT.Bank Regional Development (BPD) West Sumatera Painan Branch where t arithmetic variable of work motivation bigger than t table (titung 2,181>t table 1,9883) or its significance is less than alpha $(0.035$ <0.05). Partially work discipline has a positive and significant effect to the performance of employees of PT.Bank Regional Development (BPD) West Sumatera Painan Branch where $t$ arithmetic variable work discipline is greater than t table ( $t$ count 4,636> t table 1,9883) or siginifikansinya smaller than alpha $(0,000<0.05)$, and the regression equation for these three variables is $\hat{Y}=26.445+0.299 X 1+$ $0.220 \times 2 .+0.409 \times 3$.
\end{abstract}

Keywords: Leadership Style, Work Motivation, Work Discipline and Employee Performance

\begin{abstract}
ABSTRAK
Penelitian Ini Bertujuan Untuk Mengungkapan Pengaruh Gaya Kepemimpinan, Motivasi Kerja Dan Disiplin Kerja Terhadap Kinerja Pegawai. Populasi penelitian ini adalah semua pegawai Pada PT.Bank Pembangunan Daerah (BPD) Sumatera Barat Cabang Painan yang berjumlah 45 orang. Sampel diambil dari semua populasi yaitu 45 orang. Metode análisis menggunakan análisis regresi berganda. Hasil penelitian didapatkan : Secara berganda didapatkan pengaruh variabel X secara bersama- sama terhadap variabel Y pada PT.Bank Pembangunan Daerah (BPD) Sumatera Barat Cabang Painan adalah sebesar 0,573 atau 57,3 $\%$ dengan Sig. $\mathrm{F}$ sebesar $0,000<0,05$ atau nilat $\mathrm{Ft}_{\text {hitung }}$ lebih besar dari $\mathrm{F}_{\text {tabel }}$ yaitu $26.445>3,34$, maka dapat dikatakan bahwa gaya kepemimpinan $\left(\mathrm{X}_{1}\right)$ motivasi kerja $\left(\mathrm{X}_{2}\right)$ dan disiplin kerja $(\mathrm{X} 3)$ terbukti berpengaruh secara positif dan signifikan terhadap Kinerja karyawan PT.Bank Pembangunan Daerah (BPD) Sumatera Barat Cabang Painan. Secara parsial gaya kepemimpinan berpengaruh positif dan signifikan terhadap Kinerja karyawan PT.Bank Pembangunan Daerah (BPD) Sumatera Barat Cabang Painan dimana $t_{\text {hitung }}$ variabel gaya kepemimpinan lebih besar dari $t_{\text {tabel }}\left(t_{\text {hitung }} 2,713>t_{\text {tabel }} 1,9883\right)$ atau siginifikansinya lebih kecil dari alpha $(0,010<0,05)$. Secara parsial motivasi kerja berpengaruh positif dan signifikan terhadap Kinerja karyawan PT.Bank Pembangunan Daerah (BPD) Sumatera Barat Cabang

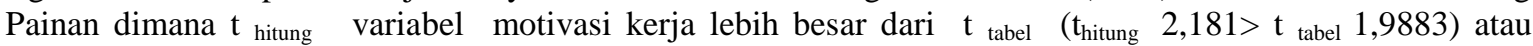
siginifikansinya lebih kecil dari alpha $(0,035<0,05)$. Secara parsial disiplin kerja berpengaruh positif dan signifikan terhadap Kinerja karyawan PT.Bank Pembangunan Daerah (BPD) Sumatera Barat Cabang Painan dimana $t_{\text {hitung }}$ variabel disiplin kerja lebih besar dari $t$ tabel $(t$ hitung 4,636> $t$ tabel 1,9883) atau siginifikansinya lebih kecil dari alpha $(0,000<0,05)$, dan persamaan regresi untuk ketiga variabel tersebut adalah $\hat{Y}=26,445+0,299 \mathrm{X}_{1}+0,220 \mathrm{X}_{2}+0,409 \mathrm{X}_{3}$.
\end{abstract}

Kata Kunci: Gaya Kepemimpinan,Motivasi Kerja, Disiplin Kerja dan Kinerja Karyawan 


\section{PENDAHULUAN}

Perbankan merupakan lembaga yang bergerak pada jasa keuangan. Lembaga ini selain mengumpulkan uang masyarakat juga memberikan kredit kepada masyarakat baik untuk kepentingan konsumtif maupun untuk kegiatan usaha. Setiap lembaga baik yang berorientasi keuntungan maupun non profit selalu membutuhkan dana dalam upaya untuk dapat menjalankan aktivitasnya. Tanpa ketersediaan dana organisasi tidak akan dapat berjalan dengan baik. Apalagi organisasi yang berorintasi pada profit (kegiatan usaha) dalam menjalankan aktivitasnya selalu membutuhkan dana guna membiayai usahanya. Dana tersebut dapat dipenuhi dengan sumber intern perusahaan, suntikan dari pemilik perusahaan maupun dari pinjaman ke Bank.

Begitu juga dengan PT. Bank Pembangunan Daerah (BPD) Sumatera Barat CabangPainan, fungsinya juga mengumpulkan uang dan memberikan kridit kepada masyarakat,untuk melaksanakan fungsi tersebut PT. Bank Pembangunan Daerah (BPD) Sumatera Barat CabangPainan membutuhkan sumberdaya manusia yang terampil dan berdedikasi tinggi untuk menhasilkan kinerja yang tinggi. Pada umumnya kinerja diartikan sebagai kesuksesan seseorang dalam melaksanakan suatu pekerjaan. Menurut Sentoso (2005), kinerja adalah hasil kerja yang dapat dicapai oleh seseorang atau kelompok orang dalam suatu organisasi sesuai dengan wewenang dan tanggung jawab masing-masing dalam rangka upaya mencapai tujuan organisasi. Kinerja individu dengan kinerja organisasi terdapat hubungan yang erat, dengan kata lain bila kinerja karyawan baik maka kemungkinan besar kinerja organisasi juga baik.

Permasalahan mengenai kinerja merupakan permasalahan yang akan selalu dihadapi oleh pihak manajemen perusahaan, karena itu manajemen perlu mengetahui faktor-faktor yang mempengaruhi kinerja karyawan. Faktor-faktor yang dapat mempengaruhi kinerja karyawan tersebut akan membuat manajemen perusahaan dapat mengambil berbagai kebijakan yang diperlukan, sehingga dapat meningkatkan kinerja karyawannya agar sesuai dengan harapan perusahaan. Ravianto (2008) menyebutkan faktor-faktor yang mempengaruhi kinerja karyawan diantaranya yaitu pendidikan dan latihan, disiplin, sikap dan aktivitas kerja,motivasi, masa kerja, gizi dan kesehatan, tingkat penghasilan, jaminan sosial, lingkungan kerja, disiplin kerja, teknologi dan sarana produksi, kesempatan kerja, serta kebutuhan untuk berprestasi, komunikasi, gaya kepemimpinan. Dalam penelitian ini penulis bertujuan untuk meneliti gaya kepemimpinan, motivasi kerja dan disiplin kerja dan pengaruhnya terhadap kinerja karyawanPT. Bank Pembangunan Daerah (BPD) Sumatera Barat CabangPainan

\section{TINJAUAN PUSTAKA}

Amar (2004), dalam Mamik, (2010) menyatakan bahwa pemimpin perusahaan perlu memperhatikan gaya kepemimpinan yang digunakannya dalam mendorong dan mengarahkan bawahannya agar kinerja mereka meningkat, sehingga mutu produk yang mereka hasilkan juga meningkat. Keberhasilan suatu organisasi dalam mencapai tujuannya sangat ditentukan oleh gaya kepemimpinan seorang pemimpin. Gaya kepemimpinan berkaitan dengan cara yang digunakan oleh pimpinan untuk mengatur dan mempengaruhi karyawan untuk meningkatkan kinerja mereka dalam rangka pencapaian tujuan organisasi. Pemimpin memiliki hubungan yang sangat erat dengan motivasi karyawan. Pemimpin yang baik akan mendorong, memelihara, mempertahankan, dan meningkatkan motivasi dan kinerja karyawan dengan selalu memperhatikan karyawannya agar tercipta hubungan yang harmohis antara atasan dengan bawahan.

\section{METODE PENELITIAN}

Metode yang digunakan dalam penelitian ini adalah metode survei sedangkan bentuk penelitiannya adalah Penelitian Deskriptif. Penelitian deskritif dilakukan dengan menggunakan teknik korelasi. Teknik ini dilakukan untuk menganalisa hubungan antara tiga variabel bebas yakni gaya kepemimpinan $\left(\mathrm{X}_{1}\right)$ Motivasi kerja $\left(\mathrm{X}_{2}\right)$ dan disiplin kerja $\left(\mathrm{X}_{3}\right)$ dan satu variabel terikat yaitu kinerja karyawan Bank Pembanngunan Daerah Kota Painan. Populasi dan sampel dalam penelitian ini adalah seluruh karyawan PT.Bank Pembangunan Daerah (BPD) Sumatera Barat Cabang Painan yang berjumlah 45 orang. Adapun kisi-kisi instrumen yang akan diteliti dapat dilihat pada tabel berikut : 


\begin{tabular}{|c|c|c|c|c|}
\hline Variabel & Indikator & Sumber & $\underset{\mathbf{h}}{\text { Jumla }}$ & $\begin{array}{c}\text { Nomor } \\
\text { Pertanyaan }\end{array}$ \\
\hline $\begin{array}{c}\text { Kinerja } \\
\text { Karyawan }\end{array}$ & $\begin{array}{l}\text { a) Pengetahuan tentang pekerjaan, } \\
\text { b) Cara melaksanakan pekerjaan, } \\
\text { c) Kesanggupan Menyelesaikan tugas yang } \\
\text { dibebankan. } \\
\text { d) Waktu yang digunakan. }\end{array}$ & $\begin{array}{l}\text { Timpe } \\
(2005)\end{array}$ & $\begin{array}{l}3 \\
3 \\
3 \\
3\end{array}$ & $\begin{array}{r}1,2,3 \\
4,5,6 \\
7,8,9 \\
10,11,12\end{array}$ \\
\hline $\begin{array}{c}\text { Gaya } \\
\text { kepemimpina } \\
\mathrm{n}\end{array}$ & $\begin{array}{l}\text { a) Sistem nilai organisasi, } \\
\text { b) Rasa yakin dan percaya terhadap } \\
\text { bawahan, } \\
\text { c) Kecendrungan kepemimpinan, } \\
\text { d) Perasaan aman dalam situasi tertentu. }\end{array}$ & $\begin{array}{l}\text { Stoner } \\
(2008) \text {, }\end{array}$ & $\begin{array}{l}3 \\
3 \\
3 \\
3\end{array}$ & $\begin{array}{c}1,2,3 \\
4,5,6 \\
7,8,9 \\
10,11,12\end{array}$ \\
\hline $\begin{array}{c}\text { Motivasi } \\
\text { kerja }\end{array}$ & $\begin{array}{l}\text { a) Semangat dalam melaksanakan tugas, } \\
\text { b) Meningkatkan prestasi kerja, } \\
\text { c)Produktif dalam bekerja, } \\
\text { d) Bertanggungjawab terhadap } \\
\text { pekerjaan }\end{array}$ & $\begin{array}{l}\text { Sedarma } \\
\text { yanti } \\
(2007)\end{array}$ & $\begin{array}{l}3 \\
3 \\
3 \\
3\end{array}$ & $\begin{array}{c}1,2,3 \\
4,5,6 \\
7,8,9 \\
10,11,12\end{array}$ \\
\hline Disiplin kerja & $\begin{array}{l}\text { a) Kedisiplinan terhadap ketentuan atau } \\
\text { ketaatan, } \\
\text { b) Kedisiplinan pada peraturan dan tata } \\
\text { tertib, dan } \\
\text { c) Kedisiplinan terhadap peningkatan usaha } \\
\text { kerja sama. }\end{array}$ & $\begin{array}{l}\text { Prijoda } \\
\text { rminto, } \\
\text { (2007). }\end{array}$ & $\begin{array}{l}4 \\
4 \\
4\end{array}$ & $\begin{array}{c}1,2,3,4 \\
5,6,7,8 \\
9,10,11,12\end{array}$ \\
\hline
\end{tabular}

Dalam pengujian hipotesis penelitian, digunakan uji regresi linear berganda. Adapun tujuan menggunakan analisa regresi berganda dalam penelitian ini adalah untuk mengetahui bagaimana dampak variabel motivasi kerja, disiplin dan buaya organisasi baik secara parsial maupun secara simultan terhadap Kinerja karyawan PT Bank Pembangunan Daerah Sumatera Barat Cabang Painan. Dengan demikian, dapat dikemukakan persamaan regresi linear berganda dalam penelitian ini adalah sebagai berikut:

$\mathbf{Y}=\mathbf{a}+\mathbf{b}_{1} \mathbf{X}_{1}+\mathbf{b}_{2} \mathbf{X}_{2}+\mathbf{b}_{3} \mathbf{X}_{3}+e$

Dimana,

$\begin{array}{lll}\mathrm{Y} & = & \text { Kinerja Karyawan } \\ \mathrm{a} & = & \text { Konstanta } \\ \mathrm{b}_{1,2,3} & = & \text { Koefisien regresi } \\ \mathrm{X}_{1} & = & \text { Gaya kepemimpinan } \\ \mathrm{X}_{2} & = & \text { Motivasi kerja } \\ \mathrm{X}_{3} & = & \text { Disiplin Kerja } \\ \mathrm{e} & & \text { error }\end{array}$

\section{HASIL PENELITIAN PEMBAHASAN}

Koefisien korelasi merupakan suatu teknik statistik yang digunakan untuk mengukur keeratan hubungan antar variabel (Kuncoro, 2006). Dalam penelitian ini, untuk mengetahui hubungan antara variabel yaitu motivasi kerja, disiplin dan Gaya kepemimpinan terhadap variabel kinerja karyawan digunakan korelasi bivariat melalui metode Person's correlation. Hasil analisa koefisien korelasi tersebut disajikan pada tabel 2.

\begin{tabular}{lll}
\multicolumn{3}{l}{ Tabel 2.Uji Koefisien Korelasi } \\
\hline Variabel & $\begin{array}{l}\text { Kinerja } \\
\text { pegawai } \\
\end{array}$ & $\begin{array}{l}\text { Tingkat } \\
\text { Signifikansi }\end{array}$ \\
& 0.564 & 0.000 \\
\hline $\begin{array}{l}\text { Gaya } \\
\text { kepemimpinan(X1) }\end{array}$ & & \\
$\begin{array}{l}\text { Motivasi kerja } \\
\text { (X2) }\end{array}$ & 0.336 & 0.009 \\
Disiplin Kerja (X3) & 0.653 & 0.000 \\
\hline Sumber: Data & Primer & yang duolah
\end{tabular}




\section{Uji Multikolonieritas}

Tabel 3.Uji Multikolonieritas

\begin{tabular}{lll}
\hline Variabel bebas & Tolerance & VIF \\
Gaya kepemimpinan(X1) & .795 & 1.258 \\
Motivasi kerja (X2) & .979 & 1.022 \\
Disiplin kerja (X3) & .803 & 1.245 \\
\hline
\end{tabular}

Sumber: Data Primer yang diolah.

Berdasarkan tabel diatas dapat dilihat bahwa variabel bebas dalam penelitian ini dinyatakan bebas dari moltikolonieritas. Hal ini terbukti dengan didapatkannya nilai tolerence untuk semua variabel bebas lebih besar dari 0,10 dan nilai VIF (variance inflation factor) kurang dari 10.

\section{Uji Heteroskedastisitas}

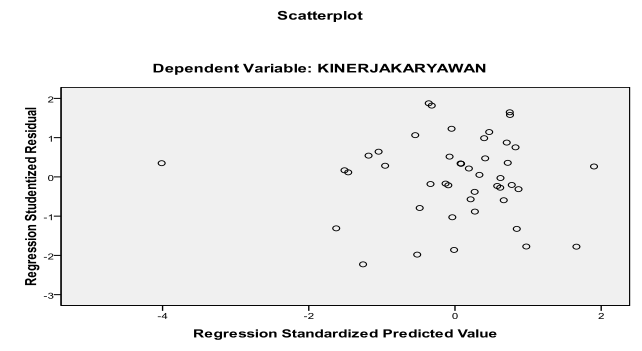

\section{Uji Normalitas}

Histogram

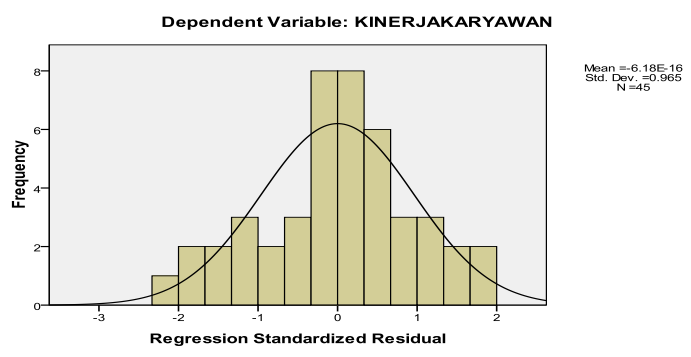

terlihat bahwa data observasi terdistribusi dengan normal dimana kurvanya adalah normal. Oleh karena itu uji normalitas terpenuhi.

\section{Uji Linearitas}

$$
\begin{gathered}
\text { Normal P-P Plot of Regression Standardized } \\
\text { Residual }
\end{gathered}
$$

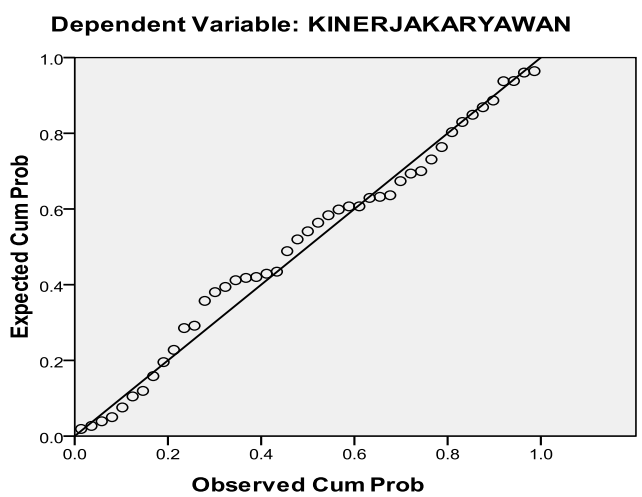

\section{Uji Hipotesis}

Menurut Sekaran (2006) Hipotesis merupakan dugaan tentang hubungan yang logis antara dua variabel atau lebih yang dinyatakan dalam bentuk pernyataan yang perlu diuji kebenarannya.

Berdasarkan grafik histogram tersebut,

\begin{tabular}{|c|c|c|c|c|c|c|c|}
\hline \multirow[b]{2}{*}{ Model } & \multicolumn{2}{|c|}{$\begin{array}{l}\text { Unstandardized } \\
\text { Coefficients }\end{array}$} & \multicolumn{3}{|c|}{$\begin{array}{l}\text { Standardized } \\
\text { Coefficients }\end{array}$} & \multicolumn{2}{|c|}{$\begin{array}{l}\text { Collinearity } \\
\text { Statistics }\end{array}$} \\
\hline & $\mathrm{B}$ & Std. Error & Beta & $\mathrm{t}$ & Sig. & Tolerance & VIF \\
\hline 1 (Constant) & $\begin{array}{l}26.44 \\
5\end{array}$ & 7.507 & & 3.523 & .001 & & \\
\hline $\begin{array}{l}\text { Gaya } \\
\text { kepemimpinan }\end{array}$ & .299 & .110 & .310 & 2.713 & .010 & .795 & 1.258 \\
\hline
\end{tabular}

Tabel 4 Coefficients ${ }^{\mathrm{a}}$ 


\begin{tabular}{llllllll} 
Motivasi kerja & .220 & .101 & .225 & 2.181 & .035 & .979 & 1.022 \\
Disiplin kerja & .409 & .088 & .528 & 4.636 & .000 & .803 & 1.245 \\
\hline
\end{tabular}

\section{A. Dependent Variable: Kinerjakaryawan}

Dari tabel 4 di atas terlihat nilai $t_{\text {hitung }}$ 2,713 lebih besar dari $t_{\text {tabel }}(2,713>1,9883)$ dengan tingkat signifikan lebih kecil dari alpha $(0,010<0,05)$, maka Ho ditolak dan $\mathrm{H}_{\mathrm{a}}$ diterima. Artinya, secara parsial ada pengaruh yang positif dan signifikan antara Gaya kepemimpinan $\left(\mathrm{X}_{1}\right)$ terhadap kinerja karyawan.(Y). Oleh karena itu hipotesis pertama yang menyatakan "Gaya kepemimpinan secara parsial berpengaruh positif dan signifikan terhadap kinerja kayawan pada PT.Bank Pembangunan Daerah (BPD) Sumatera Barat Cabang Painan “ diterima. Koefisien regresi dari Gaya kepemimpinan adalah 0,299, dan hal ini dapat diinterpetasikan bahwa setiap peningkatan 1 unit variabel gaya kepemimpinan akan meningkatkan kinerja karyawan sebesar 0,299 unit, demikian pula dengan keadaan sebaliknya.

Dari tabel 4 di atas terlihat nilai $\mathrm{t}_{\text {hitung }}$ 2,181 lebih besar dari $t_{\text {tabel }}(2,181>1,9883)$ dengan tingkat signifikan lebih kecil dari alpha $(0,035<0,05)$, maka Ho ditolak dan $\mathrm{H}_{\mathrm{a}}$ diterima. Artinya, secara parsial ada pengaruh yang positif dan signifikan antara motivasi kerja $\left(\mathrm{X}_{2}\right)$ terhadap kinerja karyawan (Y). Oleh karena itu hipotesis kedua yang menyatakan " Motivasi kerja secara parsial berpengaruh positif dan signifikan terhadap kinerja kayawan pada PT.Bank Pembangunan Daerah (BPD) Sumatera Barat Cabang Painan

diterima”. Koefisien regresi dari kompetensi adalah 0,220 hal ini dapat diinterpetasikan bahwa setiap peningkatan 1 unit variabel motivasi kerja akan meningkatkan kinerja karyawan sebesar 0,220 unit, demikian pula dengan keadaan sebaliknya.

Dari tabel $4 \mathrm{di}$ atas terlihat nilai $\mathrm{t}_{\text {hitung }}$ 4,636 lebih besar dari $t_{\text {tabel }}(4.636>1,9883)$ dengan tingkat signifikan lebih kecil dari alpha $(0,000<0,05)$, maka Ho ditolak dan $\mathrm{H}_{\mathrm{a}}$ diterima. Artinya, secara parsial ada pengaruh yang positif dan signifikan antara disiplin kerja $\left(\mathrm{X}_{3}\right)$ terhadap kinerja karyawan (Y). Oleh karena itu hipotesis keempat yang menyatakan “ displin kerja secara parsial berpengaruh positif dan signifikan terhadap kinerja kayawan pada PT.Bank Pembangunan Daerah (BPD) Sumatera Barat Cabang Painan " diterima". Koefisien regresi dari pengawasan adalah 0,409,dan hal ini dapat diinterpetasikan bahwa setiap peningkatan 1 unit variabel disiplin kerja akan meningkatkan kinerja karyawan sebesar 0,409 unit, demikian pula dengan keadaan sebaliknya.

Tabel 5. Model Summary gaya kepemimpinan, motivasi kerja dan disiplin kerja dan kinerja karyawan pada PT.Bank Pembangunan Daerah (BPD) Sumatera Barat Cabang Painan

\begin{tabular}{lllll}
\multicolumn{3}{l}{ Model Summary } \\
\hline Model & R & R Square & Adjusted R Square & Std. Error of the Estimate \\
\hline 1 & $.757^{\mathrm{a}}$ & .573 & .542 & 4.095 \\
\hline A. Predict &
\end{tabular}

A. Predictors: (Constant), Disiplinkerja, Motivasikerja, gaya kepemimpinan

B. Dependent Variable: Kinerja karyawan

Berdasarkan Tabel. 5 di atas diperoleh bahwa koefisien $\mathrm{R}$ adalah $(0,757)$ yaitu terdapat hubungan yang kuat dan positif antara Gaya Kemimpinan motivasi kerja dan disiplin kerja secara bersama sama erhadap kinerja karyawan dan nilai koefisien determinan atau $\mathrm{R}$ square $/ \mathrm{R}^{2}$ adalah 0,573 $(57,3 \%)$ yang berarti bahwa kontribusi pengaruh Gaya kepemimpinan, motivasi kerja dan disiplin kerja secara serentak terhadap kinerja karyawan adalah sebesar $57,3 \%$ dan sisanya $42,7 \%$ di pengaruhi oleh faktor lain yang tidak termasuk dalam ruang lingkup penelitian ini. Untuk mengetahui apakah Gaya kepemimpinan, motivasi kerja dan disiplin kerja berpengaruh positif dan signifikan terhadap kinerja karyawan dapat dilihat dari tabel 6 dibawah ini. 
TABEL 6 ANOVA

\begin{tabular}{llllll}
\hline Model & Sum of Squares & df & Mean Square & F & Sig. \\
\hline 1 Regression & 923.133 & 3 & 307.711 & 18.346 & $.000^{\mathrm{a}}$ \\
Residual & 687.667 & 41 & 16.772 & & \\
Total & 1610.800 & 44 & & & \\
\hline
\end{tabular}

A. Predictors: (Constant), Disiplin kerja, Motivasi kerja, Gaya Kepemimpinan

B. Dependent Variable: Kinerjakaryawan

Dari tabel diatas dapat lihat nilai $\mathrm{F}$ hitung sebesar 18,346 dengan tingkat signifikansi sebesar 0,000. Jika nilai signifikan dibanding dengan tingkat signifikan yang digunakan pada penelitian ini dengan alpha 0,05 , maka terbukti bahwa nilai signifikansi lebih kecil dari tingkat signifikansi yang digunakan $(0,000<0,05)$. Maka Ho ditolak dan Ha diterima yang berarti Gaya kepemimpinan (X1), motivasi kerja (X2) dan disiplin kerja (X3) secara bersama-sama berpengaruh positif dan signifikan terhadap kinerja karyawan. Sehingga hipotesis pertama yang menyatakan " Gaya kepemimpinan, motivasi kerja dan disiplin kerja secara bersama-sama berpengaruh positif dan signifikan terhadap kinerja kayawan pada PT.Bank Pembangunan Daerah (BPD) Sumatera Barat Cabang Painan "diterima. Berdasarkan tabel diatas dapat diperoleh persamaan regresinya sebagai berikuti $\hat{Y}=26,445+0,299 X_{1}+0,220$ $\mathrm{X}_{2 .}+0,409 \mathrm{X}_{3}$ dimana

$$
\begin{aligned}
& \hat{\mathrm{Y}}^{\prime}=\text { Kinerja Karyawan } \\
& \mathrm{X}_{1}=\text { Gaya kepemimpinan } \\
& \mathrm{X}_{2}=\text { Motivasi kerja } \\
& \mathrm{X}_{3}=\text { Disiplin Kerja }
\end{aligned}
$$$$
\text { Selanjutnya ke empat (4) hipotesis }
$$
penelitian yang dikemukakan sebelumnya dapat disimpulkan seperti pada tabel berikut.

\section{Pengaruh Gaya kepemimpinanTerhadap Kinerja Pegawai}

Hasil pengujian hipotesis penelitian yang menyatakan bahwa "Terdapat pengaruh yang positif dan signifikan secara parsial dari variabel Gaya kepemimpinan terhadap kinerja karyawan pada PT.Bank Pembangunan Daerah (BPD) Sumatera Barat Cabang Painan." terbukti kebenarannya. Hal ini bermakna bila gaya kepimpinan pada PT.Bank Pembangunan Daerah (BPD) Sumatera Barat Cabang Painan baik dan tepat dapat lebih ditingkatkan dimasa yang akan datang maka akan dapat meningkatkan kinerja karyawan
PT.Bank Pembangunan Daerah (BPD) Sumatera Barat Cabang Painan . Dengan kata lain, semakin efektif gaya kemimpinan pada PT.Bank Pembangunan Daerah (BPD) Sumatera Barat Cabang Painan, maka akan semakin tinggi kinerja karyawan PT.Bank Pembangunan Daerah (BPD) Sumatera Barat Cabang Painan. Hal ini berarti kinerja karyawan ditentukan secara positif oleh Gaya kepemimpinan. Jika Gaya kepemimpinan pada PT.Bank Pembangunan Daerah (BPD) Sumatera Barat Cabang Painan baik maka kinerja karyawan cenderung akan tinggi. Sesuai yang dikemukakan oleh Schein (2005) bahwa Gaya kepemimpinan adalah pola dasar yang diterima oleh organisasi untuk bertindak dan memecahkan masalah, membentuk karyawan yang mampu beradaptasi dengan lingkungan dan mempersatukan anggotaanggota organisasi. Untuk itu harus diajarkan kepada anggota termasuk anggota yang baru sebagai suatu cara yang benar dalam mengkaji, berpikir dan merasakan masalah yang dihadapi.

\section{Pengaruh Motivasi kerja Terhadap Kinerja Karyawan}

Hasil pengujian hipotesis penelitian yang menyatakan bahwa "Terdapat pengaruh yang positif dan signifikan dari variabel motivasi kerja terhadap kinerja kayawan pada PT.Bank Pembangunan Daerah (BPD) Sumatera Barat Cabang Painan terbukti kebenarannya. Hal ini ditunjukkan dengan besarnya koefisien regresi sebesar 0,220 dan sinignifikansi 0,035 lebih kecil dari $5 \% .(0,035<0,05)$. Hal ini berarti kinerja kayawan pada PT.Bank Pembangunan Daerah (BPD) Sumatera Barat Cabang Painan dipengaruhi secara positif dan signifikan oleh motivasi kerja dari karyawan PT.Bank Pembangunan Daerah (BPD) Sumatera Barat Cabang Painan. Jika motivasi kerja karyawan tinggi maka kinerja karyawan cendrung juga 
akan tinggi. Motivasi merupakan suatu kondisi yang mendorong, menggerakkan atau menjadi sebab seseorang melakukan suatu perbuatan atau kegiatan yang berlangsung secara sadar. Siagian(2007) mengemukakan bahwa " motivasi" mencakup dorongan, alasan, kemauan yang berbentuk tenaga dari dalam dari manusia yang menyebabkan manusia berbuat". Jadi motivasi merupakan suatu kekuatan atau keinginan yang sangat kuat dalam diri manusia untuk melakukan suatu pekerjaan atau kegiatan secara nyata. Apabila motivasi kerja karyawan PT.Bank Pembangunan Daerah (BPD) Sumatera Barat Cabang Painan tinggi maka karyawan akan terdorong untuk bekerja bersungguh -sungguh untuk menyelesaikan tugas sehingga menghasilkan kinerja yang tinggi.

\section{Pengaruh Disiplin Kerja Terhadap Kinerja Karyawan}

Hasil pengujian hipotesis penelitian yang menyatakan bahwa "Terdapat pengaruh yang positif dan signifikan dari variabel disiplin kerja terhadap kinerja karyawan pada PT.Bank Pembangunan Daerah (BPD) Sumatera Barat Cabang Painan.terbukti kebenarannya. Hal ini ditunjukkan dengan besarnya koefisien regresi sebesar 0,409 dengan signifikan 0,000 lebih kecil dari 5\% $(0,000<0,05)$. Hal ini berarti kinerja karyawan pada PT.Bank Pembangunan Daerah (BPD) Sumatera Barat Cabang Painan. ditentukan secara positif dan signifikan oleh disiplin kerja dari para karyawan itu sendiri.. Jika disiplin kerja dari para karyawan baik, patuh terhadap peraturan yang ditetapkan PT.Bank Pembangunan Daerah (BPD) Sumatera Barat Cabang Painan, maka kinerja yang ditunjukan dan dihasilkan oleh karyawan juga akan tinggi.

Sesuai yang dikemukakan oleh Veithzal
(2009) bahwa disiplin yang baik mencerminkan besarnya tanggung jawab terhadap tugas yang diberikan kepadanya. Hal ini mendorong gairah kerja dan semangat kerja dan terwujudnya tujuan perusahaan, karyawan serta masyarakat pada umumnya. Melalui disiplin akan mencerminkan kekuatan, karena biasanya seseorang yang berhasil memiliki disiplin yang tinggi adalah orang yang konsekuen dan konsisten serta bertanggung jawab dan taat kepada asas atas pekerjaan yang diamanatkan kepadanya. Oleh karena itu demi terwujudnya tujuan perusahan diperlukan karyawan pada PT.Bank Pembangunan Daerah (BPD) Sumatera Barat Cabang Painan yang memiliki tingkat kedisiplinan yang tinggi. Jadi kedisiplinan menjadi kunci sukses perusahaan dalam mencapai tujuannya.

\section{Pengaruh gaya kepemimpinan, Motivasi kerja dan disiplin kerja Terhadap Kinerja Karyawan}

Hasil penelitian menemukan bahwa secara bersama sama terdapat pengaruh yang positif dan signifikan antara Gaya kepemimpinan, motivasi kerja dan disiplin kerja terhadap kinerja karyawan PT.Bank Pembangunan Daerah (BPD) Sumatera Barat Cabang Painan, semakin sefektif gaya kepemimpinan dari pimpinan PT.Bank Pembangunan Daerah (BPD) Sumatera Barat Cabang Painan, semakin tinggi motivasi kerja dan disiplinkerja karyawan maka akan semakin tinggi pula kinerja yang dihasilkan karyawan PT.Bank Pembangunan Daerah (BPD) Sumatera Barat Cabang Painan.

Sumbangan secara bersama-sama antara variabel Gaya kepemimpinan, motivasi kerja dan disiplin kerja terhadap kinerja pegawai adalah sebesar $57,3 \%$, dan $42,7 \%$ lainnya dipengaruhi oleh variabel lain yang tidak diteliti seperti iklim organisasi, lingkungan kerja, supervisi, pelatihan,budaya organisasi, pengembangan karier, kompensasi, komitmen organisasi dan lain-lainnya.

\section{SIMPULAN}

Berdasarkan hasil analisis eksternal dan internal dengan matrik SWOT dan F-AHP dapat disimpulkan sebagai berikut:

Hasil analisa dengan menggunakan SWOT tentang alternative strategi pemasaran songket Silungkang Sumatra Barat didapat sebuah konsep pemikiran tentang menggali semua potensi untuk meminimalkan kelemahan serta menggunakan kekuatan untuk memanfaatkan peluang dan menghadapi ancaman. Alternatif strategi pemasaran songket Silungkang terdiri dari strategi jangka pendek (WT), strategi jangka menengah (ST,WO) dan strategi jangka panjang (SO).

Dari hasil simulasi pemilihan strategi pemasaran terbaik songket Silungkang Sumatra Barat didapatkan nilai sebagai berikut: $\mathrm{WT}$ nilai $=3.44$, ST nilai $=3.39$, OS nilai $=3.33$, SW nilai $=3.32$. 


\section{DAFTAR PUSTAKA}

Andi. 2005. "Jaringan Syaraf Tiruan dan

Pemogramannya Menggunakan

Matlab",Yogyakarta.

Afrillita T, Nur. 2013. Analisis SWOT

Dalam menentukan Strategi Pemasaran

Sepeda Motor Pada PT. Samekarindo Indah

di Samarinda. Jurnal. Universitas

Mulawarman. Samarinda

Anauta 2014 " SISTEM PENDUKUNG

KEPUTUSAN PEMILIHAN STRATEG

PENGEMBANGAN INDUSTRI

GALANGAN KAPAL TRADISIONAL DI MADURA MENGGUNAKAN METODE

SWOT DAN F-AHP “ semnas IENACO

Jasril, Haerani, E., \& Afrianty, L. (2009).

Sistem Pendukung Keputusan (Spk)

Pemilihan Karyawan Terbaik Menggunakan

Metode Fuzzy Ahp (F- Ahp). Seminar Nasional Aplikasi Teknologi Informasi 2011, 2011(Snati 2011), 17-18.

Buchari, Alma, 2000, Manajemen

Pemasaran dan Pemasaran Jasa, Cetakan

Kelima, Bandung : Alfabeta

Dharmesta, Basu Swastha, 2002, Azasazas Marketing, Yogyakarta : Liberty

Hamidi, Kambiz dan Delbahari, Vahideh. 2011. Formulating a Strategy for a University Using SWOT Technique: a Case Study. Jurnal. HBIAU. Hamedan

Hartati,Sri.2006.'Fuzzy Multi Attribute Decision Making",Yogyakarta.

Jasril, Haerani, E., \& Afrianty, L. (2009).

Sistem Pendukung Keputusan (Spk) Pemilihan Karyawan Terbaik Menggunakan Metode

Fuzzy Ahp (F- Ahp). Seminar Nasional Aplikasi Teknologi Informasi 2011, 2011(Snati 2011), 17-18.

Juanim, 2004, Analisis Jalur dalam Riset Pemasaran, Bandung : Universitas Pasundan

Kusumadewi,Sri. 2013 ."Aplikasi Logika Fuzzy”,Yogyakarta.

Lumbangaol, R. A. ( 2013). SISTEM PENDUKUNG KEPUTUSAN PENANGANAN GIZI BURUK PADA BALITA MENGGUNAKAN METODE FUZZY MAMDANI Volume : IV, Nomor: 2.

Mardison.2012."Sistem Pendukung Keputusan Dalam Pencairan Kredit Nasabah Bank dengan Menggunakan Logika Fuzzy dan Bahasa Pemograman Java".
Proverawati,Atikah. 2011 .’Ilmu Gizi untuk Keperawatan \& Gizi Kesehatan", Yogyakarta.

Sejati, Y. (2008). IMPLEMENTASI FUZZY SET DAN FUZZY INFEKENCE SYSTEMTSUKAMOTO PADA PENE,NTUAN HARGA BELI HANDPHONE BEKAS (Vol.

VOLUME 4 ): Jurnal Informatika.

Saladin, Djaslim, 2006, Manajemen Pemasaran, Edisi Keempat, Bandung : Linda Karya

Vasantha WICKRAMASINGHE, S.-e. T. (2008). Application of Combined SWOT and Analytic 